\title{
The adverse effect of emergency department crowding on compliance with the resuscitation bundle in the management of severe sepsis and septic shock
}

Tae Gun Shin ${ }^{1}$, Ik Joon Jo ${ }^{1 *}$, Dae Jong Choi', Mun Ju Kang ${ }^{1}$, Kyeongman Jeon ${ }^{2}$, Gee Young Suh' , Min Seob Sim', So Yeon Lim³, Keun Jeong Song ${ }^{1}$ and Yeon Kwon Jeong ${ }^{1}$

\begin{abstract}
Introduction: The aim of this study is to evaluate the effects of emergency department (ED) crowding on the implementation of tasks in the early resuscitation bundle during acute care of patients with severe sepsis and septic shock, as recommended by the Surviving Sepsis Campaign guidelines.

Methods: We analyzed the sepsis registry from August 2008 to March 2012 for patients presenting to an ED of a tertiary urban hospital and meeting the criteria for severe sepsis or septic shock. The ED occupancy rate, which was defined as the total number of patients in the ED divided by the total number of ED beds, was used for measuring the degree of ED crowding. It was categorized into three groups (low; intermediate; high crowding). The primary endpoint was the overall compliance with the entire resuscitation bundle.

Results: A total of 770 patients were enrolled. Of the eligible patients, 276 patients were assigned to the low crowding group, 250 patients to the intermediate crowding group, and 244 patients to the high crowding group (ED occupancy rate: $\leq 115 ; 116-149 ; \geq 150 \%)$. There was significant difference in compliance rates among the three groups (31.9\% in the low crowding group, $24.4 \%$ in the intermediate crowding group, and $16.4 \%$ in the high crowding group, $P<0.001$ ). In a multivariate model, the high crowding group had a significant association with lower compliance (adjusted odds ratio (OR), $0.44 ; 95 \%$ confidence interval $(C \mathrm{I}), 0.26$ to $0.76 ; P=0.003)$. When the ED occupancy rate was included as a continuous variable in the model, it had also a negative correlation with the overall compliance (OR of $10 \%$ increase of the ED occupancy rate, $0.90 ; 95 \% \mathrm{Cl}, 0.84$ to $0.96, P=0.002$ ).
\end{abstract}

Conclusions: ED crowding was significantly associated with lower compliance with the entire resuscitation bundle and decreased likelihood of the timely implementation of the bundle elements.

\section{Introduction}

Severe sepsis and septic shock are life-threatening illnesses with a high mortality rate, whose incidence appears to be increasing in recent years [1-3]. Early identification and effective management in a timely fashion are key factors for improving survival in these patients [4-6]. Currently, the Surviving Sepsis Campaign (SSC) guidelines recommend implementing a resuscitation bundle to provide more

\footnotetext{
* Correspondence: driji@skku.edu

${ }^{1}$ Department of Emergency Medicine, Samsung Medical Center,

Sungkyunkwan University School of Medicine, Seoul, Korea

Full list of author information is available at the end of the article
}

rapid and qualified care. This bundle includes serum lactate measurement, early blood cultures and antibiotics, and early goal-directed therapy (EGDT) $[4,7,8]$. Compliance with the resuscitation bundle has been shown to reduce mortality, particularly when more components of the resuscitation bundle are accomplished within specific time limits [4,8-10].

Various barriers may interfere with the compliance and quality in the management of severe sepsis and septic shock $[11,12]$. In particular, emergency department (ED) crowding, which is one of the factors known to decrease the quality of the ED process, may have a potential effect

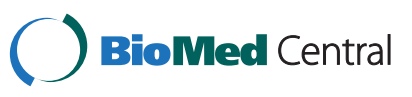

(c) 2013 Shin et al.; licensee BioMed Central Ltd. This is an open access article distributed under the terms of the Creative Commons Attribution License (http://creativecommons.org/licenses/by/2.0), which permits unrestricted use, distribution, and reproduction in any medium, provided the original work is properly cited. 
on the care of sepsis patients [13,14]. Previous studies have shown that ED crowding delays appropriate care for several populations including the time required for administration of antibiotics for pneumonia patients and febrile neonates, for brain imaging in patients with acute stroke, for percutaneous coronary intervention for acute myocardial infarction, and for analgesia in adults with severe pain [15-19]. However, the association between ED crowding and compliance with the resuscitation bundle has not been determined.

The objective of this study was to evaluate the effects of ED crowding on the implementation of tasks in the early resuscitation bundle during acute care of patients with severe sepsis and septic shock. We hypothesized that the degree of ED crowding was associated with the rate of achievement of the resuscitation bundle.

\section{Methods}

We analyzed the sepsis registry for patients presenting to the ED and meeting the criteria for severe sepsis or septic shock and data were prospectively collected from August 2008 to March 2012 at Samsung Medical Center (a 1,960 bed, university-affiliated, tertiary referral hospital with 70,000 annual ED visits in Seoul, South Korea). There are 58 beds for patients including hallway spaces in the ED of the study hospital (50 beds in the adult zone and eight beds for the pediatric zone). The registry was previously used in our studies regarding severe sepsis and septic shock [20-22].

The study was approved by the institutional review board of Samsung Medical Center. Informed consent was waived because of the retrospective observational and anonymous nature of the study.

\section{Patient inclusion criteria}

We included patients, 18 years of age or older, who presented with septic shock or severe sepsis and blood lactate concentrations of $\geq 4 \mathrm{mmol} / \mathrm{L}$. Exclusion criteria were as follows: (1) terminal malignancy, (2) patients who had previously signed 'Do Not Resuscitate' (DNAR) orders, and (3) patients who refused the EGDT. We excluded patients with terminal malignancy because these patients are not often provided with intensive treatment, and they instead usually receive only conservative treatment.

\section{Definition}

Sepsis was defined as suspected infection in the presence of two or more systemic inflammatory response syndrome criteria [23]. Severe sepsis was defined as sepsis associated with acute organ dysfunction [24]. Septic shock was defined as persistent hypotension (systolic arterial pressure $<90 \mathrm{mmHg}$, mean arterial pressure (MAP) $<60 \mathrm{mmHg}$, or a reduction in systolic blood pressure $>40 \mathrm{mmHg}$ from baseline) despite adequate volume resuscitation [24]. Cryptic shock was defined as normotensive patients with blood lactate concentrations $\geq 4 \mathrm{mmol} / \mathrm{L}$ [25]. Initiation of EGDT was defined as central line insertion followed by measurement of central venous oxygen saturation $\left(\mathrm{Scvo}_{2}\right)$ within six hours from the time of meeting the criteria for resuscitation [12].

\section{Resuscitation protocol and bundle}

A protocol for early recognition and appropriate management of patients with severe sepsis or septic shock was provided for the ED physician, included in our previous study [22], and was based on the protocol by Rivers et al. [6]. We recommended delivery of the resuscitation bundle to hemodynamically stable sepsis patients with serum lactate levels $\geq 4 \mathrm{mmol} / \mathrm{L}$ or systolic BP $<90 \mathrm{mmHg}$ after initial volume resuscitation, based on the 2008 SSC guidelines [7]. Initial evaluation and resuscitation were conducted in the ED. When severe sepsis or septic shock was suspected, patients were assigned to a critical care zone in the ED, which included five beds, advanced monitoring equipment and mechanical ventilators.

The resuscitation bundle was categorized by seven interventions $[4,8,10]: 1)$ serum lactate measurement; 2 ) blood culture before antibiotic administration; 3 ) broad spectrum antibiotics administered within three hours from the time of presentation in the event of hypotension and/or lactate $\geq 4 \mathrm{mmol} / \mathrm{L}$; 4) delivery of an initial minimum volume of $20 \mathrm{ml} / \mathrm{kg}$ crystalloid (or colloid) in the event of persistent hypotension despite fluid resuscitation and/or lactate $\geq 4 \mathrm{mmol} / \mathrm{L} ; 5)$ achievement and maintenance of MAP $\geq 65 \mathrm{mmHg}$; 6) achievement of central venous pressure (CVP) $\geq 8 \mathrm{mmHg}$; and 7) achievement of $\mathrm{Scvo}_{2} \geq 70 \%$.

'Time zero' was defined as the time at which criteria for initiation of the specific intervention were met $[4,10]$. For calculating the time for lactate measurement, blood cultures, and antibiotic administration, time zero was defined as the moment of presentation, which was considered as the time of triage [8]. Time zero to initiate the EGDT was considered when either hypotension or hyperlactatemia greater than $4 \mathrm{mmol} / \mathrm{L}$ was reported.

The bundle compliance was assessed as whether or not a particular task was completed $[4,9,10]$. Compliance with each single intervention was considered as having been achieved if it was implemented within six hours from time zero, except for antibiotic therapy. Results are shown as the number of bundle interventions completed (0 to 7$)$.

\section{Emergency department crowding measurement}

The ED occupancy rate, which was defined as the total number of patients in the ED divided by the total 
number of ED beds, was used for measuring the degree of ED crowding [26]. It is a simple and validated tool for real-time assessment of crowding, and it has been widely used in other studies [15-17,19,26,27]. We tallied the total number of patients in the specific zone of the ED every hour by using an electronic medical records system. The ED occupancy rate was calculated from the number of patients in the ED at the time of triage. The occupancy rate was computed based on the adult ED section, including the waiting zone. The ED occupancy rate was categorized into tertile groups as follows: low crowding group, intermediate crowding group, and high crowding group [27]. We also examined whether the beds of the critical care zone were at full capacity when sepsis patients arrived at the ED or when they were diagnosed with severe sepsis.

If the critical care zone is at full capacity, we try to transfer the patients, who are occupying critical zone, to ICU, operating theater or general ward within the same facility to recover the capacity for the critical care zone. As a regional tertiary referral center, the study hospital does not transfer critically ill patients, including those with severe sepsis, to other hospitals.

\section{Outcome measurement}

The primary endpoint was the overall compliance of the entire resuscitation bundle. Secondary endpoints were the completion rate of each intervention, the number of bundle interventions completed, the ED length of stay (LOS), ICU LOS, in-hospital LOS, and in-hospital mortality.

\section{Data collection}

Data were obtained from our sepsis registry and electronic medical records. Potential risk factors influencing compliance with the bundle were considered when we chose variables [12,21]. We collected patient demographics, site of infection, vital signs, and laboratory data. Sequential Organ Failure Assessment (SOFA) scores were calculated at the time of severe sepsis or septic shock diagnosis from the data obtained [28]. Poor performance status was defined as confined to bed 50\% or more of waking hours. We recorded the mode of arrival (use of emergency medical service) and time variables, such as the time of presentation, time of hypotension or hyperlactatemia, and time when specific interventions were done. The time period was categorized according to the routine changes of the number of nurses and physicians. In addition, the physician's gender and the level of experience (years in the field) possessed by the physicians and nurses were also recorded.

\section{Statistical analysis}

Continuous variables were expressed as the median with interquartile ranges because the majority of the data did not follow a normal distribution. Categorical variables were expressed as numbers (percentages) of patients. Continuous variables were compared using the KruskalWallis rank test or the Wilcoxon rank-sum test according to the number of groups. Additionally, we assessed trends in the compliance, the number of completed interventions, and the implementation timing across the crowding levels using the Wilcoxon-type test for trend analysis. Categorical variables were compared with the chi-square test or the Fisher's exact test. For all multiple comparisons, $P$-values were calculated by applying a Bonferroni correction.

Unadjusted and adjusted odds ratios (ORs) for primary outcome measures were calculated by univariate and multivariate logistic regression analysis, respectively. Variables which were found to be statistically significant at $P<0.10$ using univariate analysis were selected and included in the final multivariate models. Several variables were mandatorily adjusted regardless of $P$-value, including age, gender, body temperature, cryptic shock, SOFA score, initial lactate level, the time period of ED arrival, physician's gender, the level of experience of physicians and nurses, and the study period. First, we made a model for the overall compliance. The probability of overall compliance was calculated from the multivariate model. Subsequently, we conducted logistic analysis for compliance with each element in the same way. The Hosmer-Lemeshow test was used to check the goodnessof-fit of the logistic regression.

Stata 12.0 was used for statistical analysis, and a twotailed $P$ value $<0.05$ was considered significant.

\section{Results}

\section{Baseline characteristics}

We identified 917 patients with severe sepsis or septic shock during the study period. We excluded 116 patients with terminal malignancy, 27 DNAR patients, and four patients who refused EGDT. Finally, a total of 770 patients were included in this study. Of eligible patients, 276 patients were assigned to the low crowding group, 250 patients to the intermediate crowding group, and 244 patients to the high crowding group (ED occupancy rate: $\leq 115 ; 116$ to $149 ; \geq 150 \%)$. The median ED occupancy rate was $132 \%$ (interquartile rage, 110 to $162 \%$ ).

Comparison of baseline characteristics among the three groups is summarized in Table 1. There were no significant differences except for the presence of chronic renal disease and the time period of ED arrival. Patients who presented during the nights or weekends were more common in the low and intermediate crowding groups.

\section{Resuscitation bundle compliance}

Compliance with the entire resuscitation bundle was $25.6 \%$ in the study population. There was a significant 
Table 1 Comparison of baseline characteristics

\begin{tabular}{|c|c|c|c|c|c|}
\hline & $\begin{array}{l}\text { Overall group } \\
\text { (number }=770 \text { ) }\end{array}$ & $\begin{array}{l}\text { Low crowding group } \\
\text { (number }=276 \text { ) }\end{array}$ & $\begin{array}{l}\text { Intermediate crowding group } \\
\quad \text { (number }=250)\end{array}$ & $\begin{array}{l}\text { High crowding group } \\
\text { (number }=244 \text { ) }\end{array}$ & $P$ \\
\hline Age (years) & 65 (55 to 73$)$ & 64 (53 to 72) & 67 (56 to 73) & 65 (54 to 74$)$ & 0.081 \\
\hline Gender (male) & $437(56.8)$ & $161(58.3)$ & $131(52.4)$ & $145(59.4)$ & 0.232 \\
\hline \multicolumn{6}{|l|}{ Comorbidities } \\
\hline Hypertension & $244(31.7)$ & $76(27.5)$ & $82(32.8)$ & $86(35.2)$ & 0.152 \\
\hline Diabetes & $165(21.4)$ & $52(18.8)$ & $56(22.4)$ & $57(23.4)$ & 0.411 \\
\hline Cardiovascular disease & $79(10.7)$ & $26(9.4)$ & $27(10.8)$ & $26(10.7)$ & 0.847 \\
\hline Chronic lung disease & $48(6.2)$ & $17(6.2)$ & $18(7.2)$ & $13(5.3)$ & 0.690 \\
\hline Chronic renal disease & $35(4.5)$ & $4(1.4)$ & $22(8.8)^{a}$ & $9(3.7)$ & $<0.001$ \\
\hline Chronic hepatic disease & $67(8.7)$ & $19(6.9)$ & $21(8.4)$ & $27(11.1)$ & 0.235 \\
\hline Metastatic solid cancer & $194(25.2)$ & 65 (23.6) & $58(23.3)$ & $71(29.1)$ & 0.241 \\
\hline Hematologic malignancy & 99 (12.9) & $36(13.1)$ & 29 (11.6) & $34(13.9)$ & 0.734 \\
\hline Organ transplantation & $14(1.8)$ & $6(2.2)$ & $3(1.2)$ & $5(2.1)$ & 0.667 \\
\hline Neutropenia (ANC $<500 \mathrm{~mm}^{3}$ ) & $131(17.0)$ & $48(17.4)$ & $42(16.8)$ & $41(16.8)$ & 0.978 \\
\hline Nursing home resident & $29(3.8)$ & $9(3.7)$ & $9(3.6)$ & $11(4.5)$ & 0.741 \\
\hline Poor performance status & $35(4.6)$ & $11(4.0)$ & $12(4.8)$ & $12(4.9)$ & 0.854 \\
\hline Suspected infection focus & & & & & 0.259 \\
\hline Intra-abdominal infection & $288(37.4)$ & $112(40.6)$ & $92(36.8)$ & $84(34.4)$ & \\
\hline Pneumonia & $218(28.3)$ & $77(27.9)$ & $71(28.4)$ & $70(28.7)$ & \\
\hline Urinary tract infection & $115(14.9)$ & $40(14.5)$ & $44(17.6)$ & $31(12.7)$ & \\
\hline Others & $149(19.3)$ & $47(17.0)$ & $43(17.2)$ & $59(24.2)$ & \\
\hline \multicolumn{6}{|l|}{ Initial vital signs } \\
\hline Mean arterial pressure $(\mathrm{mmHg})$ & 66 (58 to 80$)$ & 66 (58 to 81$)$ & 65 (57 to 78$)$ & $67(59$ to 81$)$ & 0.185 \\
\hline Heart rate (per minute) & 112 (95 to 130$)$ & 115 (96 to 135$)$ & 109 (94 to 126) & 112 (95 to 130$)$ & 0.065 \\
\hline Respiratory rate (per minute) & 20 (20 to 24$)$ & 20 (20 to 24$)$ & 20 (20 to 24$)$ & 20 (19 to 24$)$ & 0.271 \\
\hline Body temperature $\left({ }^{\circ} \mathrm{C}\right)$ & 38.0 (36.8 to 38.9$)$ & 38.3 (37.0 to 38.9 ) & 37.9 (36.7 to 38.8$)$ & 37.9 (36.8 to 38.9$)$ & 0.165 \\
\hline Initial presentation of cryptic shock & $288(37.4)$ & $103(37.2)$ & $95(38.0)$ & $90(36.9)$ & 0.967 \\
\hline Initial serum lactate (mmol/L) & 4.3 (2.5 to 5.7 ) & 4.4 (2.8 to 5.8$)$ & 4.4 (2.4 to 5.7$)$ & $4.2(2.5$ to 5.4$)$ & 0.531 \\
\hline SOFA score & 7 (4 to 9 ) & $7(4$ to 10$)$ & $7(4$ to 9$)$ & $7(4$ to 9$)$ & 0.458 \\
\hline Mechanical ventilation & $87(11.3)$ & $32(11.6)$ & $28(11.2)$ & $27(11.1)$ & 0.980 \\
\hline \multicolumn{6}{|l|}{ Time period of initial presentation } \\
\hline Night (10 PM to 7 AM) & $191(24.8)$ & $122(44.2)$ & $60(24.0)^{a}$ & $9(3.7)^{\mathrm{ab}}$ & $<0.001$ \\
\hline Weekend & $227(29.5)$ & $162(58.7)$ & $58(23.2)^{a}$ & $7(2.9)^{\mathrm{ab}}$ & $<0.001$ \\
\hline Physician's experience & & & & & 0.217 \\
\hline$\leq 2^{\text {nd }}$ year residents & $602(78.2)$ & $212(76.8)$ & $190(76.0)$ & $200(82.0)$ & \\
\hline$\geq 3^{\text {rd }}$ year residents or & $168(21.8)$ & $64(23.2)$ & $60(24.0)$ & $44(18.0)$ & \\
\hline \multicolumn{6}{|l|}{ board-certified physicians } \\
\hline Physician's gender (male) & $381(49.5)$ & $135(48.9)$ & $114(45.6)$ & $132(54.1)$ & 0.163 \\
\hline Nurse's experience & & & & & 0.115 \\
\hline 0 to about 2 years & $397(51.6)$ & $152(55.3)$ & $136(54.4)$ & $109(44.7)$ & \\
\hline 3 to about 5 years & $215(28.0)$ & $73(26.6)$ & $67(26.8)$ & $75(30.7)$ & \\
\hline More than 5 years & $157(20.4)$ & $50(18.2)$ & $47(18.8)$ & $60(24.6)$ & \\
\hline Use of EMS & $247(32.2)$ & $88(32.1)$ & $81(32.4)$ & $78(32.1)$ & 0.997 \\
\hline
\end{tabular}


Table 1 Comparison of baseline characteristics (Continued)

\begin{tabular}{|c|c|c|c|c|c|}
\hline Study period & & & & & 0.221 \\
\hline 2008 to about 2009 & $291(37.8)$ & $104(37.7)$ & $104(41.6)$ & $83(34.0)$ & \\
\hline 2010 to about 2012 & $479(62.2)$ & $172(62.3)$ & $146(58.4)$ & $161(66.0)$ & \\
\hline Critical care zone at full capacity & $55(7.1)$ & $9(3.3)$ & $10(4.0)$ & $36(14.6)$ & $<0.001$ \\
\hline ED occupancy rate (\%) & 132 (110 to 162$)$ & $100(92$ to 111$)$ & 136 (126 to 142$)$ & 172 (163 to 187$)$ & \\
\hline
\end{tabular}

difference in compliance rates between the three groups (31.9\% in the low crowding group, $24.4 \%$ in the intermediate crowding group, and $16.4 \%$ in the high crowding group, $P<0.001, P$ for trend $=0.007$ ) (Figure 1 ). In particular, the absolute difference between the low group and the high crowding group was $15.5 \%(P<0.001)$. Among the elements of the resuscitation bundle, the completion rates of early administration of antibiotics and the achievement of $\mathrm{Scvo}_{2} \geq 70 \%$ were significantly lower in the high crowding group than in the low crowding group $(P=0.009$ and $P=0.006$, respectively) and also showed significant decreasing trends.

The number of completed interventions in the bundle was significantly lower in the high crowding group compared with the low $(P<0.001)$ and intermediate crowding groups $(P=0.013)$ (Table 2$)$. When we analyzed the time intervals from time zero to the implementation of each bundle component according to tertile, there were consistently increasing trends toward the time intervals from time zero to lactate measurement $(P=0.007)$, blood cultures $(P=0.038)$, broad-spectrum antibiotic use $(P=0.005)$, fluid challenge $(P=0.036)$, the achievement of $\mathrm{CVP} \geq 8 \mathrm{mmHg}(P=0.003)$, use of vasopressors $(P=0.004)$, and the achievement of $\mathrm{Scvo}_{2} \geq 70 \%(P=0.016)$.

\section{Logistic regression analysis}

The uni- and multivariable analyses for the overall compliance are shown in Table 3. After adjusting for potential confounders, the high ED crowding was associated with lower sepsis care compliance (adjusted OR, 0.44 ; $95 \%$ confidence interval (CI), 0.26 to $0.76 ; P=0.003$ ) (Table 3). When we conducted a stratified analysis based on physician experience, which might have interactions with crowding, we found a significant correlation between crowding and compliance in all subgroups (adjusted OR, 0.50 (95\% CI, 0.26 to $0.96 ; P=0.037$ ) in the subgroup of physician's experience $\leq 2^{\text {nd }}$ year residents and adjusted OR, 0.25 (95\% CI, 0.08 to $0.72 ; P=0.010)$ in the subgroup of physician's experience $\geq 3^{\text {rd }}$ year residents).

When the ED occupancy rate was included as a continuous variable in the model, instead of the tertiles, it also had a negative correlation with the overall compliance (OR of $10 \%$ increase of the ED occupancy rate, 0.90 ; $95 \% \mathrm{CI}, 0.84$ to $0.96, P=0.002$ ). Predicted probabilities of the overall compliance according to the ED occupancy rate are shown in Figure 2.

Additional regression models revealed that the high crowding group or higher ED occupancy rates were significantly associated with decreasing compliance with bundle elements, including early broad-spectrum antibiotics and the achievement of $\mathrm{Scvo}_{2} \geq 70 \%$ (Table 4).

\section{Length of stay and in-hospital mortality}

There was a significant trend toward increasing ED LOS over the tertiles $(P=0.002)$ (Table 5). As for in-hospital stay, the differences or trends were statistically marginal,

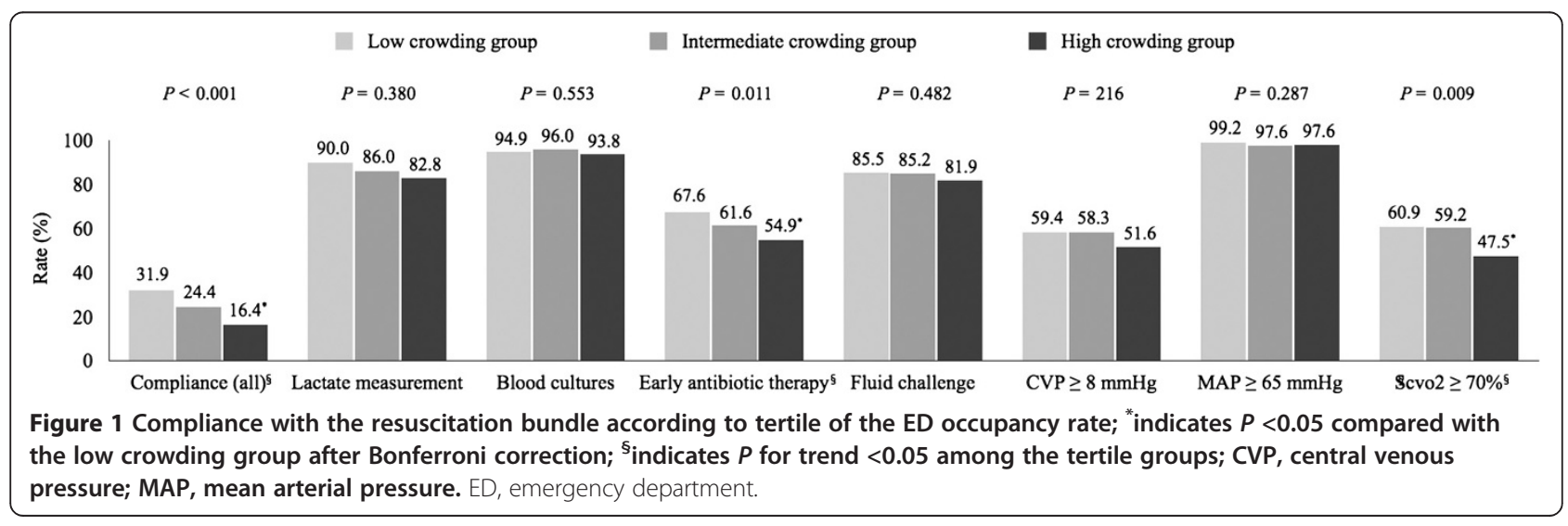


Table 2 Number of completed interventions and the time intervals from time zero to the implementation of each bundle component

\begin{tabular}{|c|c|c|c|c|c|}
\hline & $\begin{array}{c}\begin{array}{c}\text { Overall } \\
\text { group }\end{array} \\
\text { (number }=770 \text { ) }\end{array}$ & $\begin{array}{l}\text { Low crowding } \\
\text { group } \\
\text { (number }=276 \text { ) }\end{array}$ & $\begin{array}{c}\text { Intermediate crowding } \\
\text { group } \\
(\text { number }=250)\end{array}$ & $\begin{array}{l}\text { High crowding } \\
\text { group } \\
\text { (number }=244 \text { ) }\end{array}$ & $P$ \\
\hline Number of interventions of the bundle accomplished ${ }^{c}$ & $5(4$ to 6$)$ & $6(5$ to 7$)$ & $6(5$ to 6$)$ & $5(4 \text { to } 6)^{\mathrm{ab}}$ & $<0.001$ \\
\hline \multicolumn{6}{|l|}{ Time to the implementation $^{\mathrm{d}}$ (hours) } \\
\hline Serum lactate measurement ${ }^{c}$ & $1.3(0.8)$ & $1.2(0.8$ to 2.5$)$ & $1.3(0.9$ to 3.0$)$ & $1.4(0.9$ to 3.6$)$ & 0.023 \\
\hline Blood cultures ${ }^{c}$ & $1.2(0.8$ to 2.1$)$ & $1.2(0.8$ to 1.9$)$ & $1.2(0.8$ to 2.3$)$ & 1.3 (0.9 to 2.2$)$ & 0.109 \\
\hline Broad-spectrum antibiotics $^{c}$ & 2.5 (1.7 to 3.8$)$ & $2.4(1.5$ to 3.5$)$ & $2.6(1.7$ to 3.9$)$ & $2.8(1.8$ to 4.2$)$ & 0.018 \\
\hline Intravenous fluid challenge ${ }^{c}(n=649)$ & $0.6(0.1$ to 1.5$)$ & $0.6(0.1$ to 1.5$)$ & $0.6(0.1$ to 1.6$)$ & $0.8(0.2$ to 1.6$)$ & 0.109 \\
\hline CVP $\geq 8 \mathrm{mmHg}$ achieved $^{\mathrm{c}}(\mathrm{n}=546)$ & $2.9(1.7$ to 5.5$)$ & 2.5 (1.5 to 5.0$)$ & 2.7 (1.5 to 4.9$)$ & $3.5(2.0 \text { to } 6.8)^{\mathrm{ab}}$ & 0.005 \\
\hline Use of vasopressors ${ }^{c}(n=473)$ & 2.1 (1.1 to 3.4$)$ & $1.8(1.0$ to 3.1$)$ & $1.9(1.1$ to 3.1$)$ & $2.4(1.4 \text { to } 4.2)^{\mathrm{ab}}$ & 0.003 \\
\hline Scvo $_{2} \geq 70 \%$ achieved $^{c}(n=573)$ & 3.5 (1.9 to 6.6$)$ & 3.3 (1.7 to 5.7$)$ & 3.5 (2.0 to 5.8$)$ & $4.2(1.9$ to 6.5$)$ & 0.051 \\
\hline
\end{tabular}

Data are shown as median with interquartile range or number (\%). ${ }^{\mathrm{a}} P<0.05$ compared with the low crowding group after Bonferroni correction; ${ }^{\mathrm{b}} P<0.05$ compared with the intermediate crowding group after Bonferroni correction; ${ }^{c} P$ for trend $<0.05$ among the tertile groups; ${ }^{d}$ calculated beyond the specific time limits. CVP, central venous pressure; MAP, mean arterial pressure.

although there were similar tendencies. In-hospital mortality rates were $16.3 \%$ in the low crowding group, $14.4 \%$ in the intermediate crowding group, and $18.4 \%$ in the high crowding group, respectively $(P=0.478)$. The mortality rate was slightly higher in the high crowding group compared with the other groups combined (low and intermediate crowding group), but these differences were not statistically significant $(18.4 \%$ versus $15.4 \%, P=0.288)$. If we considered only days and evenings on weekdays when ED crowding was more severe, there was a significant difference among the three groups $(P=0.019)$. In particular, the mortality rate of the high crowding group was significantly higher than that in the intermediate crowding group during this time period $(P=0.045)$.

\section{Discussion}

Our study showed that ED crowding was associated with poor compliance with the resuscitation bundle, which was based on key SSC guideline elements for management of severe sepsis and septic shock [8]. The achievement of each bundle task was delayed as the level of ED crowding increased. This resulted in a reduction of the completion rate of the entire bundle, which potentially implies a low quality in sepsis care.

To save vital organs and lives, treatment is clearly timesensitive for patients with severe sepsis and septic shock, as well as acute stroke or acute myocardial infarction $[7,18,19]$. Primary goals of initial management are early recognition and resuscitation to optimize hemodynamic status within the first few hours, which are represented by the SSC resuscitation bundle. This bundle remains a challenge to perform and has not been widely adopted in practice, although it was associated with performance improvement in sepsis care, and the reported hospital mortality rates were reduced $[4,5,9,10,29-31]$.
Accomplishing the goals of bundle application within the specific time limits requires prompt and effective coordination of hospital resources. ED crowding causes resource shortage and interferes with the ED process in the care of patients with sepsis, which might be the plausible mechanisms linking ED crowding to sepsis care $[13,19]$. Hence, as our study showed, ED crowding may delay critical ED services during management of severe sepsis and septic shock.

Most of all, it is an important finding that the rate of early antibiotic use was negatively affected by ED crowding since there are number of studies that showed delay in antibiotics affects overall mortality of sepsis patients $[4,8,32,33]$. Because there is a possibility that an antibiotic delay could be a mechanism by which ED crowding might affect outcomes of patients with sepsis, further studies on this are needed.

We also found several significant factors associated with compliance, such as body temperature, initial presentation of cryptic shock, and the experience of the physician or nurse. The results are consistent with our previous research [21]. In addition to ED crowding, these might be important factors that should be focused on in future interventions.

In a previous study [21], we did not find a significant association between ED crowding and compliance, but it included a smaller number of patients and limited data. We examined overcrowding of the entire ED, and the primary outcome was less strict (adherence to six or seven interventions). We, therefore, performed a multifactorial reanalysis focusing on ED crowding of specific sections and the overall compliance with the entire resuscitation bundle.

To solve the ED crowding problem, multi-factorial, hospital-wide approaches are needed, such as increasing 
Table 3 Univariate and multivariate analyses for overall compliance with the entire resuscitation bundle

\begin{tabular}{|c|c|c|c|c|}
\hline \multirow[t]{2}{*}{ Variable } & \multicolumn{2}{|c|}{ Univariate } & \multicolumn{2}{|c|}{ Multivariate } \\
\hline & Unadjusted OR (95\% Cl) & $P$ & Adjusted OR (95\% Cl) & $P$ \\
\hline \multicolumn{5}{|l|}{ Tertile groups of crowding } \\
\hline Low & Reference & & Reference & \\
\hline Intermediate & 0.69 (0.46 to 1.01$)$ & 0.058 & $0.70(0.45$ to 1.09$)$ & 0.116 \\
\hline High & $0.41(0.27$ to 0.64$)$ & $<0.001$ & 0.44 (0.26 to 0.76$)$ & 0.003 \\
\hline Age $>65$ years & 1.15 (0.83 to 1.61$)$ & 0.382 & 1.16 (0.82 to 1.66$)$ & 0.391 \\
\hline Female gender & 1.02 (0.73 to 1.42$)$ & 0.901 & 1.15 (0.82 to 1.67$)$ & 0.429 \\
\hline \multicolumn{5}{|l|}{ Comorbidities } \\
\hline Hypertension & 1.14 (0.80 to 1.62$)$ & 0.460 & & \\
\hline Diabetes & $0.86(0.57$ to 1.30$)$ & 0.475 & & \\
\hline Cardiovascular disease & $0.90(0.52$ to 1.56$)$ & 0.701 & & \\
\hline Chronic lung disease & $0.60(0.27$ to 1.30$)$ & 0.193 & & \\
\hline Chronic renal disease & 1.07 (0.49 to 2.32$)$ & 0.869 & & \\
\hline Chronic hepatic disease & 0.64 (0.34 to 1.24$)$ & 0.190 & & \\
\hline Metastatic solid cancer & 0.81 (0.55 to 1.20$)$ & 0.295 & & \\
\hline Hematologic malignancy & 1.05 (0.65 to 1.71$)$ & 0.842 & & \\
\hline Organ transplantation & 0.51 (0.11 to 2.30$)$ & 0.381 & & \\
\hline Neutropenia (ANC $<500 \mathrm{~mm}^{3}$ ) & $0.90(0.57$ to 1.40$)$ & 0.631 & & \\
\hline Nursing home resident & 0.79 (0.32 to 1.98$)$ & 0.621 & & \\
\hline Poor performance status & 0.62 (0.26 to 1.53$)$ & 0.302 & & \\
\hline \multicolumn{5}{|l|}{ Suspected infection focus } \\
\hline Others & Reference & & & \\
\hline Intra-abdominal infection & 0.98 (0.62 to 1.57$)$ & 0.962 & & \\
\hline Pneumonia & 0.86 (0.53 to 1.42$)$ & 0.559 & & \\
\hline Urinary tract infection & 1.48 (0.86 to 2.56$)$ & 0.150 & & \\
\hline Heart rate $>100$ per minute & 0.90 (0.63 to 1.27$)$ & 0.545 & & \\
\hline Respiratory rate $>24$ per minute & 1.03 (0.68 to 1.56$)$ & 0.886 & & \\
\hline Body temperature $>38.0^{\circ} \mathrm{C}$ & 1.50 (1.07 to 2.09$)$ & 0.016 & $1.68(1.17$ to 2.40$)$ & 0.005 \\
\hline Initial presentation of cryptic shock & 0.35 (0.24 to 0.52$)$ & $<0.001$ & 0.39 (0.24 to 0.65$)$ & $<0.001$ \\
\hline Lactate $>4 \mathrm{mmol} / \mathrm{L}$ & 0.55 (0.40 to 0.78$)$ & 0.001 & 0.80 (0.53 to 1.22$)$ & 0.311 \\
\hline SOFA score $\geq 8$ & 1.93 (1.38 to 2.69$)$ & $<0.001$ & $1.46(1.00$ to 2.13$)$ & 0.051 \\
\hline Mechanical ventilation & $0.72(0.41$ to 1.25$)$ & 0.251 & & \\
\hline Time period, night (10 PM to $7 \mathrm{AM}$ ) & $1.34(0.92$ to 1.94$)$ & 0.116 & 0.93 (0.60 to 1.42$)$ & 0.725 \\
\hline Time period, weekend & 1.47 (1.03 to 2.10$)$ & 0.032 & 1.24 (0.81 to 1.92$)$ & 0.313 \\
\hline \multicolumn{5}{|l|}{ Physician's experience } \\
\hline$\leq 2^{\text {nd }}$ year residents & Reference & & Reference & \\
\hline$\geq 3^{\text {rd }}$ year residents or & 2.51 (1.74 to 3.63$)$ & $<0.001$ & 2.85 (1.90 to 4.28$)$ & $<0.001$ \\
\hline \multicolumn{5}{|l|}{ Board-certified physicians } \\
\hline Physician's gender (male) & 0.93 (0.67 to 1.29$)$ & 0.673 & 0.83 (0.58 to 1.19$)$ & 0.318 \\
\hline \multicolumn{5}{|l|}{ Nurse's experience } \\
\hline 0 to about 2 years & Reference & & Reference & \\
\hline 3 to about5 years & 1.38 (0.94 to 2.01$)$ & 0.093 & 1.56 (1.04 to 2.36$)$ & 0.030 \\
\hline More than 5 years & 1.01 (0.65 to 1.58 ) & 0.948 & 1.16 (0.73 to 1.88$)$ & 0.604 \\
\hline
\end{tabular}


Table 3 Univariate and multivariate analyses for overall compliance with the entire resuscitation bundle (Continued)

\begin{tabular}{|c|c|c|c|c|}
\hline Use of EMS & $1.12(0.79-1.60)$ & 0.496 & & \\
\hline \multicolumn{5}{|l|}{ Study period } \\
\hline 2008 to about 2009 & Reference & & Reference & \\
\hline 2010 to about 2012 & 0.98 (0.70 to 1.37$)$ & 0.921 & 1.19 (0.82 to 1.73$)$ & 0.369 \\
\hline Critical care zone at full capacity & $0.66(0.33$ to 1.35$)$ & 0.258 & & \\
\hline
\end{tabular}

ANC absolute neutrophil count; $\mathrm{Cl}$, confidence interval; EMS, emergency medical service; OR, odds ratio; SOFA, Sequential Organ Failure Assessment.

resources and demand management [13]. For instance, a multidisciplinary response team including experienced physicians or nurses and effective hospital bed management could be beneficial. In future studies, we should evaluate interventions to improve compliance with the bundle when crowding is severe.

Early admission to the ICU could be helpful for avoiding ED crowding. However, ED crowding usually occurred when there was a lack of ICU or general ward capacity, and thus the ED input of patients increased. The study hospital has also been experiencing a problem with a shortage of ICU beds as well as ED crowding. Although patients with severe sepsis or septic shock were given priority to the critical care unit in the ED, this practice did not prevent the delay of important interventions.

Reported ED occupancy rates have been diverse, with the median rate being 80 to approximately $110 \%$ in some studies [19,26,27]. Little is known about the ED occupancy rate thresholds at which adverse crowding effects occur, and they may vary with each hospital because each ED has different resource structures or capacities, and adverse effects occur when the degree of crowding exceeds these relative capacities. Therefore, although the results cannot be generalized to other EDs, this study showed that crowding could have negative effects on the quality of sepsis care. In addition, the ED calculation of occupancy rate in this study included all patients in the waiting zone. This could be why the ED occupancy rate was higher than the rates reported in other studies.

The patient population with severe sepsis or septic shock might be displaced from receiving care in the dedicated care zone by other critically ill patients. We found that the critical care zone was more often filled to capacity in the high crowding group. When we additionally adjusted for this through multivariate analysis, there was no change in the association between ED crowding and compliance. Even though this was not a significant factor in this study, further investigation is required regarding whether too many critically ill patients in an ED affect the quality of sepsis care regardless of ED crowding.

Our study has several limitations as a single-center, retrospective, observational study. First, there might be effects of unobserved bias that we were unable to fully control, and data collection was partially dependent on the accuracy of documentation in the medical records. Second, the results may not be readily applicable to other institutions that have different settings and should

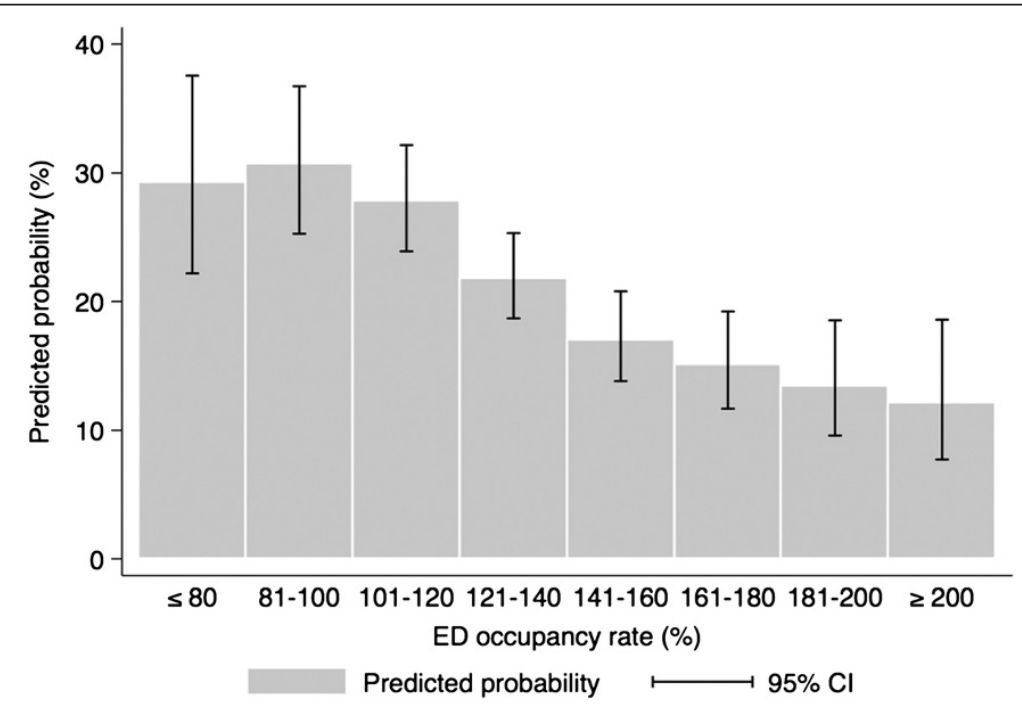

Figure 2 Predicted probabilities of compliance with the resuscitation bundle according to the emergency occupancy rate; $\mathrm{Cl}$, confidence interval. 
Table 4 Adjusted odds ratio for the completion of each intervention of the resuscitation bundle

\begin{tabular}{|c|c|c|}
\hline Variables & Adjusted OR (95\% Cl) & $P$ \\
\hline \multicolumn{3}{|l|}{ Serum lactate measurement } \\
\hline Intermediate crowding group ${ }^{a}$ & 0.91 (0.51 to 1.63$)$ & 0.747 \\
\hline High crowding group ${ }^{a}$ & 0.73 (0.38 to 1.41$)$ & 0.346 \\
\hline ED occupancy rate $(+10 \%)^{b}$ & 0.95 (0.88 to 1.03$)$ & 0.206 \\
\hline \multicolumn{3}{|l|}{ Blood cultures before antibiotics } \\
\hline Intermediate crowding group ${ }^{a}$ & $1.31(0.52$ to 3.30$)$ & 0.561 \\
\hline High crowding group ${ }^{a}$ & $0.80(0.30$ to 2.16$)$ & 0.659 \\
\hline ED occupancy rate $(+10 \%)^{\mathrm{b}}$ & $0.98(0.86$ to 1.10$)$ & 0.711 \\
\hline \multicolumn{3}{|l|}{ Early broad-spectrum antibiotics } \\
\hline Intermediate crowding group ${ }^{a}$ & $0.76(0.50$ to 1.15$)$ & 0.193 \\
\hline High crowding group ${ }^{a}$ & $0.57(0.35$ to 0.91$)$ & 0.019 \\
\hline ED occupancy rate $(+10 \%)^{b}$ & 0.93 (0.88 to 0.98$)$ & 0.018 \\
\hline \multicolumn{3}{|l|}{ Intravenous fluid challenge } \\
\hline Intermediate crowding group ${ }^{a}$ & $1.20(0.60$ to 2.39$)$ & 0.603 \\
\hline High crowding group ${ }^{a}$ & $0.86(0.40$ to 1.84$)$ & 0.697 \\
\hline ED occupancy rate $(+10 \%)^{b}$ & 0.99 (0.91 to 1.10$)$ & 0.974 \\
\hline \multicolumn{3}{|l|}{ CVP $\geq 8 \mathrm{mmHg}$ achieved } \\
\hline Intermediate crowding group ${ }^{a}$ & 1.07 (0.69 to 1.65$)$ & 0.772 \\
\hline High crowding group ${ }^{a}$ & $0.83(0.50$ to 1.37$)$ & 0.462 \\
\hline ED occupancy rate $(+10 \%)^{b}$ & 0.95 (0.89 to 1.01$)$ & 0.095 \\
\hline \multicolumn{3}{|l|}{ MAP $\geq 65$ mmHg achieved $^{c}$} \\
\hline Intermediate crowding group ${ }^{a}$ & 0.29 (0.06 to 1.45$)$ & 0.133 \\
\hline High crowding group ${ }^{a}$ & $0.34(0.07$ to 1.79$)$ & 0.203 \\
\hline ED occupancy rate $(+10 \%)^{b}$ & $0.93(0.80$ to 1.10$)$ & 0.442 \\
\hline \multicolumn{3}{|l|}{$\mathrm{SCVO}_{2} \geq 70 \%$ achieved } \\
\hline Intermediate crowding group ${ }^{a}$ & 0.83 (0.53 to 1.29$)$ & 0.408 \\
\hline High crowding group ${ }^{a}$ & 0.42 (0.25 to 0.7$)$ & 0.001 \\
\hline ED occupancy rate $(+10 \%)^{b}$ & 0.90 (0.85 to 0.96$)$ & 0.001 \\
\hline
\end{tabular}

${ }^{a}$ Reference category was the low crowding group; ${ }^{b_{i n}}$ cluded in models instead of the tertile groups; ${ }^{C}$ Variables with significance of $P<0.05$ were adjusted without mandatory inclusion.

$\mathrm{Cl}$, confidence interval; CVP, central venous pressure; $\mathrm{ED}$, emergency department; MAP, mean arterial pressure; $\mathrm{OR}$, odds ratio. be cautiously interpreted. For hospitals with low crowding in the ED, our results cannot be directly applied. Third, the effect of ED crowding was not evaluated by using other methods. However, the ED occupancy rate showed a correlation with another validated scale reflecting the number of physicians, and it was useful to predict adverse outcomes despite its simplicity [26]. Fourth, there are dimensions of sepsis care compliance that we cannot quantify although we have broken down care to the elements of the bundle. The benefit of the bundle is probably the overall combination of interventions. Fifth, the finding that overcrowding influences patient treatments is not novel, and this is not an intervention study regarding raising compliance in cases of overcrowding. However, considering the clinical significance of the sepsis care bundle, and even standing alone, completion of the sepsis care bundle is considered to be a difficult treatment option to achieve according to several studies including recently published articles, this study has a value in that it shows an association between ED crowding and, specifically, the sepsis care bundle completion $[8,9,31]$.

\section{Conclusions}

ED crowding had adverse effects on compliance with the resuscitation bundle in the management of severe sepsis or septic shock and was significantly associated with lower compliance with the entire resuscitation bundle. ED crowding was also associated with decreased likelihood of the timely implementation of the bundle elements, including early broad-spectrum antibiotic administration and the achievement of $\mathrm{Scvo}_{2} \geq 70 \%$. Severe ED crowding might be associated with increasing in-hospital mortality.

\section{Key messages}

- ED crowding was significantly associated with lower compliance with the entire resuscitation bundle in the management of severe sepsis or septic shock.

Table 5 Length of stay and in-hospital mortality

\begin{tabular}{|c|c|c|c|c|c|}
\hline & $\begin{array}{c}\text { Overall group } \\
\text { (number }=770 \text { ) }\end{array}$ & $\begin{array}{l}\text { Low crowding group } \\
\text { (number }=276)\end{array}$ & $\begin{array}{l}\text { Intermediate crowding group } \\
\quad(\text { number }=250)\end{array}$ & $\begin{array}{l}\text { High crowding group } \\
\text { (number }=244 \text { ) }\end{array}$ & $P$ \\
\hline ED LOS, hours ${ }^{\mathrm{a}}$ & 20 (8 to 34 ) & 16 (9 to 31$)$ & 20 (8 to 36$)$ & $24(9 \text { to } 46)^{b}$ & 0.009 \\
\hline ICU LOS, days & 3 (2 to 6 ) & 3 (2 to 9) & 3 (2 to 6$)$ & 3 (2 to 6$)$ & 0.379 \\
\hline \multicolumn{6}{|l|}{ In-hospital LOS, days } \\
\hline All patients & 12 (7 to 22$)$ & 11 (7 to 20$)$ & 13 (8 to 23 ) & 12 (8 to 22 ) & 0.051 \\
\hline Survivors & 12 (8 to 22 ) & 11 (7 to 20$)$ & 13 (9 to 22$)$ & 13 (8 to 22 ) & 0.048 \\
\hline In-hospital mortality & $126(16.4)$ & $45(16.3)$ & $36(14.4)$ & 45 (18.4) & 0.478 \\
\hline
\end{tabular}

Data are shown as median with interquartile ranges or number (\%). ${ }^{a} P$ for trend $<0.05$ among the tertile groups; ${ }^{b} P<0.05$ compared with the low crowding group after Bonferroni correction. ED, emergency department; ICU, intensive care unit; LOS, length of stay. 
- ED crowding was also associated with a decreased likelihood of the timely implementation of the bundle elements.

\begin{abstract}
Abbreviations
BP: Blood pressure; Cl: Confidence interval; CVP: Central venous pressure; DNAR: Do not attempt resuscitation; ED: Emergency department; EGDT: Early goal-directed therapy; LOS: Length of stay; MAP: Mean arterial pressure; OR: Odds ratio; $\mathrm{SCVO}_{2}$ : Central venous oxygen saturation; SOFA: Sequential organ failure assessment; SSC: Surviving sepsis campaign.
\end{abstract}

\section{Competing interests}

The authors declare that they have no competing interests.

\section{Authors' contributions}

TGS collected and analyzed the data and drafted this manuscript. IJJ conceived and designed the study, analyzed the data, and wrote the final manuscript. DJC collected data and assisted with analyzing the data and drafting the manuscript. MJK collected data and assisted with analyzing the data and drafting the manuscript. $\mathrm{KJ}$ assisted with analyzing the data and drafting the manuscript. GYS assisted with analyzing the data and drafting the manuscript. MSS collected data and assisted with analyzing the data and drafting the manuscript. SYL assisted with analyzing the data and drafting the manuscript. KJS contributed to analysis and interpretation of the data. YKJ contributed to analysis and interpretation of the data. All authors have read and approved the final manuscript.

\section{Author details}

${ }^{1}$ Department of Emergency Medicine, Samsung Medical Center, Sungkyunkwan University School of Medicine, Seoul, Korea. ${ }^{2}$ Department of Critical Care Medicine and Division of Pulmonary and Critical Care Medicine, Department of Medicine, Samsung Medical Center, Sungkyunkwan University School of Medicine, Seoul, Korea. ${ }^{3}$ Department of Critical Care Medicine, Samsung Medical Center, Sungkyunkwan University School of Medicine, Seoul, Korea.

Received: 22 February 2013 Accepted: 27 August 2013 Published: 6 October 2013

\section{References}

1. Dombrovskiy VY, Martin AA, Sunderram J, Paz HL: Rapid increase in hospitalization and mortality rates for severe sepsis in the United States: a trend analysis from 1993 to 2003. Crit Care Med 2007, 35:1244-1250.

2. Angus DC, Linde-Zwirble WT, Lidicker J, Clermont G, Carcillo J, Pinsky MR: Epidemiology of severe sepsis in the United States: analysis of incidence, outcome, and associated costs of care. Crit Care Med 2001, 29:1303-1310.

3. Martin GS, Mannino DM, Eaton S, Moss M: The epidemiology of sepsis in the United States from 1979 through 2000. N Engl J Med 2003, 348:1546-1554.

4. Castellanos-Ortega A, Suberviola B, Garcia-Astudillo LA, Holanda MS, Ortiz F, Llorca J, Delgado-Rodriguez M: Impact of the Surviving Sepsis Campaign protocols on hospital length of stay and mortality in septic shock patients: results of a three-year follow-up quasi-experimental study. Crit Care Med 2010, 38:1036-1043.

5. Nguyen HB, Corbett SW, Steele R, Banta J, Clark RT, Hayes SR, Edwards J, Cho TW, Wittlake WA: Implementation of a bundle of quality indicators for the early management of severe sepsis and septic shock is associated with decreased mortality. Crit Care Med 2007, 35:1105-1112.

6. Rivers E, Nguyen B, Havstad S, Ressler J, Muzzin A, Knoblich B, Peterson E, Tomlanovich M: Early goal-directed therapy in the treatment of severe sepsis and septic shock. N Engl J Med 2001, 345:1368-1377.

7. Dellinger RP, Levy MM, Carlet JM, Bion J, Parker MM, Jaeschke R, Reinhart K, Angus DC, Brun-Buisson C, Beale R, Calandra T, Dhainaut JF, Gerlach H, Harvey M, Marini JJ, Marshall J, Ranieri M, Ramsay G, Sevransky J, Thompson BT, Townsend S, Vender JS, Zimmerman JL, Vincent JL: Surviving Sepsis Campaign: international guidelines for management of severe sepsis and septic shock: 2008. Crit Care Med 2008, 36:296-327.

8. Levy MM, Dellinger RP, Townsend SR, Linde-Zwirble WT, Marshall JC, Bion J, Schorr C, Artigas A, Ramsay G, Beale R, Parker MM, Gerlach H, Reinhart K, Silva E, Harvey M, Regan S, Angus DC: The Surviving Sepsis Campaign: results of an international guideline-based performance improvement program targeting severe sepsis. Crit Care Med 2010, 38:367-374.

9. Gao F, Melody T, Daniels DF, Giles S, Fox S: The impact of compliance with 6-hour and 24-hour sepsis bundles on hospital mortality in patients with severe sepsis: a prospective observational study. Crit Care 2005, 9:R764-R770.

10. Castellanos-Ortega A, Suberviola B, Garcia-Astudillo LA, Ortiz F, Llorca J, Delgado-Rodriguez M: Late compliance with the sepsis resuscitation bundle: impact on mortality. Shock 2011, 36:542-547.

11. Carlbom DJ, Rubenfeld GD: Barriers to implementing protocol-based sepsis resuscitation in the emergency department-results of a national survey. Crit Care Med 2007, 35:2525-2532.

12. Mikkelsen ME, Gaieski DF, Goyal M, Miltiades AN, Munson JC, Pines JM, Fuchs BD, Shah CV, Bellamy SL, Christie JD: Factors associated with nonadherence to early goal-directed therapy in the ED. Chest 2010, 138:551-558.

13. Hoot NR, Aronsky D: Systematic review of emergency department crowding: causes, effects, and solutions. Ann Emerg Med 2008, 52:126-136.

14. Cowan RM, Trzeciak S: Clinical review: Emergency department overcrowding and the potential impact on the critically ill. Crit Care 2005, 9:291-295.

15. Kennebeck SS, Timm NL, Kurowski EM, Byczkowski TL, Reeves SD: The association of emergency department crowding and time to antibiotics in febrile neonates. Acad Emerg Med 2011, 18:1380-1385.

16. Pines JM, Hollander JE: Emergency department crowding is associated with poor care for patients with severe pain. Ann Emerg Med 2008, 51:1-5.

17. Pines JM, Localio AR, Hollander JE, Baxt WG, Lee H, Phillips C, Metlay JP: The impact of emergency department crowding measures on time to antibiotics for patients with community-acquired pneumonia. Ann Emerg Med 2007, 50:510-516.

18. Kulstad EB, Kelley KM: Overcrowding is associated with delays in percutaneous coronary intervention for acute myocardial infarction. Int J Emerg Med 2009, 2:149-154.

19. Chatterjee P, Cucchiara BL, Lazarciuc N, Shofer FS, Pines JM: Emergency department crowding and time to care in patients with acute stroke. Stroke 2011, 42:1074-1080.

20. Song YH, Shin TG, Kang MJ, Sim MS, Jo IJ, Song KJ, Jeong YK: Predicting factors associated with clinical deterioration of sepsis patients with intermediate levels of serum lactate. Shock 2012, 38:249-254.

21. Kang MJ, Shin TG, Jo IJ, Jeon K, Suh GY, Sim MS, Lim SY, Song K, Jeong YK: Factors influencing compliance with early resuscitation bundle in the management of severe sepsis and septic shock. Shock 2012, 38:474-479.

22. Jeon K, Shin TG, Sim MS, Suh GY, Lim SY, Song HG, Jo IJ: Improvements in compliance with resuscitation bundles and achievement of end points after an educational program on the management of severe sepsis and septic shock. Shock 2012, 37:463-467.

23. Bone RC, Balk RA, Cerra FB, Dellinger RP, Fein AM, Knaus WA, Schein RM, Sibbald WJ: Definitions for sepsis and organ failure and guidelines for the use of innovative therapies in sepsis. The ACCP/SCCM Consensus Conference Committee. American College of Chest Physicians/Society of Critical Care Medicine. Chest 1992, 101:1644-1655.

24. Levy MM, Fink MP, Marshall JC, Abraham E, Angus D, Cook D, Cohen J, Opal SM, Vincent JL, Ramsay G: SCCM/ESICM/ACCP/ATS/SIS International Sepsis Definitions Conference. Crit Care Med 2001, 2003:1250-1256.

25. Puskarich MA, Trzeciak S, Shapiro NI, Heffner AC, Kline JA, Jones AE: Outcomes of patients undergoing early sepsis resuscitation for cryptic shock compared with overt shock. Resuscitation 2011, 82:1289-1293.

26. McCarthy ML, Aronsky D, Jones ID, Miner JR, Band RA, Baren JM, Desmond $J S$, Baumlin KM, Ding R, Shesser R: The emergency department occupancy rate: a simple measure of emergency department crowding? Ann Emerg Med 2008, 51:15-24. 24 e11-12.

27. Jo S, Kim K, Lee JH, Rhee JE, Kim YJ, Suh GJ, Jin YH: Emergency department crowding is associated with 28-day mortality in communityacquired pneumonia patients. J Infect 2012, 64:268-275.

28. Vincent JL, Moreno R, Takala J, Willatts S, De Mendonca A, Bruining H, Reinhart CK, Suter PM, Thiis LG: The SOFA (Sepsis-related Organ Failure Assessment) score to describe organ dysfunction/failure. On behalf of the Working Group on Sepsis-Related Problems of the European Society of Intensive Care Medicine. Intensive Care Med 1996, 22:707-710. 
29. De Miguel-Yanes JM, Andueza-Lillo JA, Gonzalez-Ramallo VJ, Pastor L, Munoz J: Failure to implement evidence-based clinical guidelines for sepsis at the ED. Am J Emerg Med 2006, 24:553-559.

30. Cardoso T, Carneiro AH, Ribeiro O, Teixeira-Pinto A, Costa-Pereira A: Reducing mortality in severe sepsis with the implementation of a core 6-hour bundle: results from the Portuguese community-acquired sepsis study (SACiUCI study). Crit Care 2010, 14:R83.

31. Phua J, Koh Y, Du B, Tang YQ, Divatia JV, Tan CC, Gomersall CD, Faruq MO, Shrestha BR, Gia Binh N, Arabi YM, Salahuddin N, Wahyuprajitno B, Tu ML, Wahab AY, Hameed AA, Nishimura M, Procyshyn M, Chan YH: Management of severe sepsis in patients admitted to Asian intensive care units: prospective cohort study. BMJ 2011, 342:d3245.

32. Barochia AV, Cui X, Vitberg D, Suffredini AF, O'Grady NP, Banks SM, Minneci P, Kern SJ, Danner RL, Natanson C, Eichacker PQ: Bundled care for septic shock: an analysis of clinical trials. Crit Care Med 2010, 38:668-678.

33. Kumar A, Roberts D, Wood KE, Light B, Parrillo JE, Sharma S, Suppes R, Feinstein D, Zanotti S, Taiberg L, Gurka D, Kumar A, Cheang M: Duration of hypotension before initiation of effective antimicrobial therapy is the critical determinant of survival in human septic shock. Crit Care Med 2006, 34:1589-1596.

doi:10.1186/cc13047

Cite this article as: Shin et al.: The adverse effect of emergency department crowding on compliance with the resuscitation bundle in the management of severe sepsis and septic shock. Critical Care 2013 17:R224.

\section{Submit your next manuscript to BioMed Central and take full advantage of:}

- Convenient online submission

- Thorough peer review

- No space constraints or color figure charges

- Immediate publication on acceptance

- Inclusion in PubMed, CAS, Scopus and Google Scholar

- Research which is freely available for redistribution 